\title{
Utilização medicinal da secreção ("vacina-do-sapo") do anfíbio kambô (Phyllomedusa bicolor) (Anura: Hylidae) por população não-indígena em Espigão do Oeste, Rondônia, Brasil
}

\author{
Paulo Sérgio Bernarde ${ }^{1 *}$ \\ Rosimeyri Aparecida Santos ${ }^{2}$ \\ ${ }^{1}$ Laboratório de Herpetologia, Centro Multidisciplinar \\ Campus Floresta, Universidade Federal do Acre - UFAC \\ CEP 69980-000, Cruzeiro do Sul - AC, Brasil \\ ${ }^{2}$ Unidade Mista de Saúde Massao Okamoto \\ CEP 78970-000, São Miguel do Guaporé - RO, Brasil \\ *Autor para correspondência \\ snakebernarde@hotmail.com
}

Submetido em 09/02/2009

Aceito para publicação em 22/05/2009

\section{Resumo}

Anfíbios apresentam substâncias farmacologicamente ativas em sua pele com funções de proteção contra infecções de microorganismos e predadores. Algumas tribos indígenas no Sudoeste da Amazônia utilizam a secreção de Phyllomedusa bicolor para fins medicinais. Apesar de existirem relatos sobre a utilização dessa secreção em comunidades indígenas, praticamente nada existe em literatura sobre a prática em populações não indígenas. O presente estudo tem como objetivo relatar a utilização da "vacina-do-sapo" por populações nãoindígenas em Espigão do Oeste (Rondônia). Foram entrevistadas 31 pessoas que receberam aplicações dessa vacina. A utilização da "vacina-do-sapo" em Espigão do Oeste não se trata de um hábito tradicional da região, sendo que o aplicador veio de outra parte da Amazônia. Em geral, as pessoas que utilizaram a vacina são de classe média a alta e apresentam algum nível de escolaridade (ensino fundamental, médio ou superior). Cerca de metade dos entrevistados acharam que as aplicações ajudaram no problema de saúde que as levaram a receber a vacina ou sentiram melhor disposição após o tratamento e fariam novamente as aplicações. A maioria das pessoas não conhece a espécie $P$. bicolor, da qual são retiradas as secreções para elaboração da vacina. Embora várias pessoas tenham procurado o tratamento achando que a vacina servia para tudo, suas propriedades medicinais ainda se encontram em estudo.

Unitermos: etnozoologia, etnofarmacologia, medicina tradicional, Phyllomedusa bicolor, zooterapia

\section{Abstract}

Medicinal use of secretions ("the frog vaccine") from the kambô frog (Phyllomedusa bicolor) by non-indigenous peoples in Rondônia, Brazil. Amphibians have pharmaceutically active skin secretions that protect against infections and predation. Some indigenous people in southwestern Amazonia use these secretions from $P$. bicolor for medicinal purposes. While the use of these secretions by indigenous people is relatively well-known, the use by non-indigenous peoples is very poorly studied. Here we describe the use of the "frog vaccine" by non-indigenous populations in the Brazilian state of Rondônia. Thirty-one people who had received 
this "vaccine" were interviewed. The use of this vaccine is not typical or habitual in this region, and the person who administers the vaccine must travel from another part of Amazonia. Users of the vaccine come from middle and upper social classes with reasonable levels of education (primary, secondary and university). Approximately half the people vaccinated felt that their health had improved after vaccination and if need be, they would take the vaccination again. Most of the people do not know the frog species from which the secretions are taken. While the people who use this treatment believe that it is good for any infirmity, the medicinal properties, if any, of the "frog vaccine" are under study and are still unknown.

Key words: ethnozoology, ethnopharmacology, Phyllomedusa bicolor, traditional medicine, zootherapy

\section{Introdução}

O uso de animais ou de seus produtos para fins medicinais é conhecido como zooterapia e é uma das áreas de pesquisa na etnozoologia (Alves e Rosa, 2005; Costa-Neto, 2005; Santos-Fita e Costa-Neto, 2007). Apesar de vários grupos animais serem utilizados pela população como meio de medicina alternativa, são poucos os estudos desenvolvidos no Brasil sobre esse tema (Costa-Neto, 2005; Alves et al., 2007). Dentre os vertebrados utilizados para fins medicinais nos estudos desenvolvidos no Brasil, anfíbios é o grupo menos citado pelos entrevistados (Costa-Neto e Resende, 2004; Vasconcelos-da-Silva et al., 2004; Rodrigues, 2006; Alves e Rosa, 2007; Alves et al., 2007; 2008). Nos estudos que anfíbios foram mencionados, as espécies pertenciam aos gêneros Leptodactylus (Leptodactylidae) e Rhinella (Bufonidae) (Costa-Neto e Resende, 2004; Alves e Rosa, 2007; Alves et al., 2007).

A etnofarmacologia é um ramo relativamente recente da Ciência que visa estudar o conhecimento popular sobre o uso de plantas e animais para fins medicinais e seu potencial para descoberta de medicamentos (Elisabetsky, 2003). Nas pesquisas de levantamento etnofarmacológico, os registros de usos de animais para fins medicinais podem abrir diversas linhas para investigação farmacológica de seus componentes bioativos (Rodrigues, 2006). Os anfíbios apresentam substâncias farmacologicamente ativas em sua pele com funções principais de protegê-los contra infecções de microorganismos e também como mecanismo de defesa contra predadores (Duellman e Trueb, 1994; Daly, 1998). Dentre os princípios ativos encontrados nas peles dos anfíbios, moléculas alifáticas, aromáticas e heterocíclicas, além de uma diversificada gama de esteróides, alcalóides, aminas biogênicas, derivados guanídinicos, proteínas e peptídeos são encontrados nesses animais (Clarke, 1997; Monti e Cardello, 1999; Prates e Bloch Jr., 2000).

A utilização das secreções dos anfíbios por populações indígenas foi registrada em algumas localidades amazônicas (Myers et al., 1978; Daly et al., 1992). Na região de Chocó (Colômbia), índios utilizam o veneno de Phyllobates terribilis (Dendrobatidae) para envenenar as pontas de dardos para serem lançados em zarabatanas durante caçadas (Myers et al., 1978). Algumas tribos indígenas na Amazônia utilizam as secreções de Phyllomedusa (Hylidae) para fins medicinais (Daly et al., 1992; Caramaschi e Cruz, 2002; Souza et al., 2002). Os Ticunas a usam na preparação do "curare" (Caramaschi e Cruz, 2002). No Acre, os índios Katukina chamam essas pererecas de "Kampô" ou "Kambô" e aplicam a secreção para afastar o "panema" (espécie de fraqueza ou de má sorte), dando mais vigor aos caçadores (Souza et al., 2002; Lima e Labate, 2007). Vários peptídeos têm sido isolados a partir das secreções das espécies de Phyllomedusa, principalmente com propriedades antimicrobianas (Daly et al., 1992; Amiche et al., 1994; Brandt et al., 2002; Leite et al., 2004).

O método de aplicação da secreção de Phyllomedusa bicolor em humanos é conhecido como "vacina-dosapo", "injeção-do-sapo" ou "kambô" (Souza et al,. 2002; ANVISA, 2004). A aplicação consiste em fazer pequenas queimaduras na pele da pessoa (chamadas de pontos) usando um pequeno cipó ("titica"), onde logo em seguida a secreção é colocada em contato (Daly et al., 1992; Souza et al., 2002). Apesar dos relatos da utilização das secreções de Phyllomedusa por populações indígenas (Daly et al., 1992; Souza et al., 2002), praticamente pouco se sabe em literatura sobre essa prática em populações não-indígenas. Atualmente a vacina do sapo vem sendo difundida pelo país através 
de clínicas de terapias alternativas e adeptos de religiões que utilizam a bebida ayahuaska (Lima e Labate, 2007). Nesse trabalho são apresentadas informações sobre a utilização da secreção de Phyllomedusa bicolor pela população não-indígena em Espigão do Oeste, Estado de Rondônia, Sudoeste da Amazônia, Brasil.

\section{Material e Métodos}

\section{Área de estudo}

A pesquisa foi realizada no mês de setembro de 2005, no Município de Espigão do Oeste (11³0'S; $\left.60^{\circ} 40^{\prime} \mathrm{W}\right)$, Estado de Rondônia, Sudoeste da Amazônia, Brasil (Figura 1). O município apresenta cerca de 26.000 habitantes e as principais atividades econômicas correspondem ao setor madeireiro, a pecuária e agricultura (arroz, feijão e milho) (Oliveira, 2002).

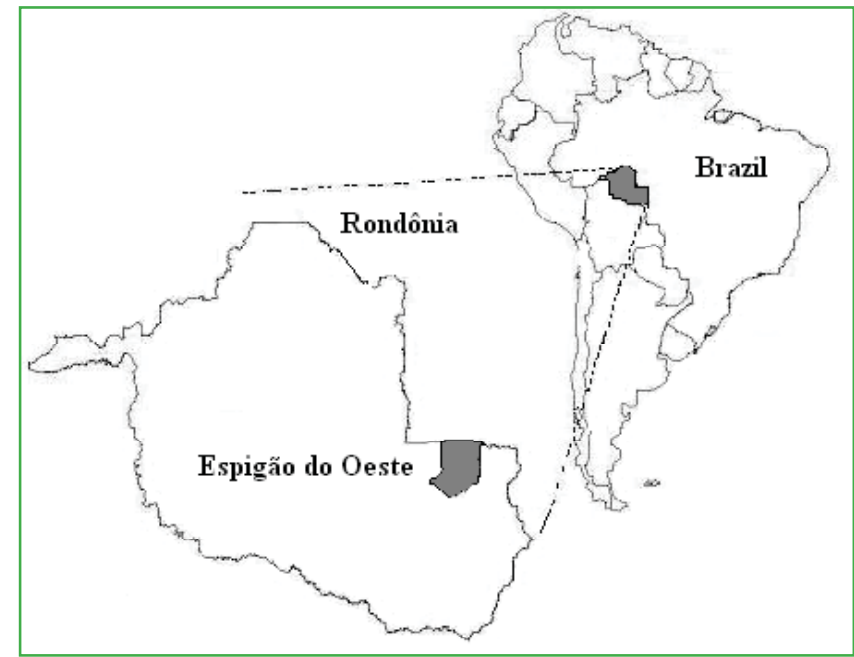

FIGURA 1: Localização do Município de Espigão do Oeste no Estado de Rondônia - Brasil.

\section{Procedimento das entrevistas}

A coleta de dados foi através de entrevistas semiestruturadas (Bernard, 1996), com a aplicação de um questionário com 17 perguntas, apresentando respostas livres e de alternativas (Anexo). Após a entrevista de um usuário, perguntava-se a ele se conhecia outro. Assim foram encontradas as pessoas que já haviam utilizado a "vacina-do-sapo". O projeto dessa pesquisa foi apresentado e aprovado ao Comitê de Ética e Pesquisa da Faculdade de Ciências Biomédicas de
Cacoal (FACIMED) em Rondônia. Os entrevistados receberam explicações sobre os objetivos da pesquisa e foram perguntados se aceitariam participar. Após o entrevistado ter aceitado participar da pesquisa, um termo de consentimento foi assinado pelo participante e pelos pesquisadores.

Para se observar se os entrevistados reconhecem a espécie utilizada para a retirada da secreção para a aplicação da vacina do sapo, foi usada uma prancha com imagens fotográficas coloridas de Phyllomedusa bicolor (Figura 2) e outras cinco espécies de anfíbios anuros da Amazônia: Adelphobates quinquevittatus (Dendrobatidae), Rhinella marina (Bufonidae), Leptodactylus pentadactylus (Leptodactylidae), Scinax ruber e Trachycephalus venulosus (Hylidae) que ocorrem no município de Espigão do Oeste, Rondônia (Bernarde, 2007).

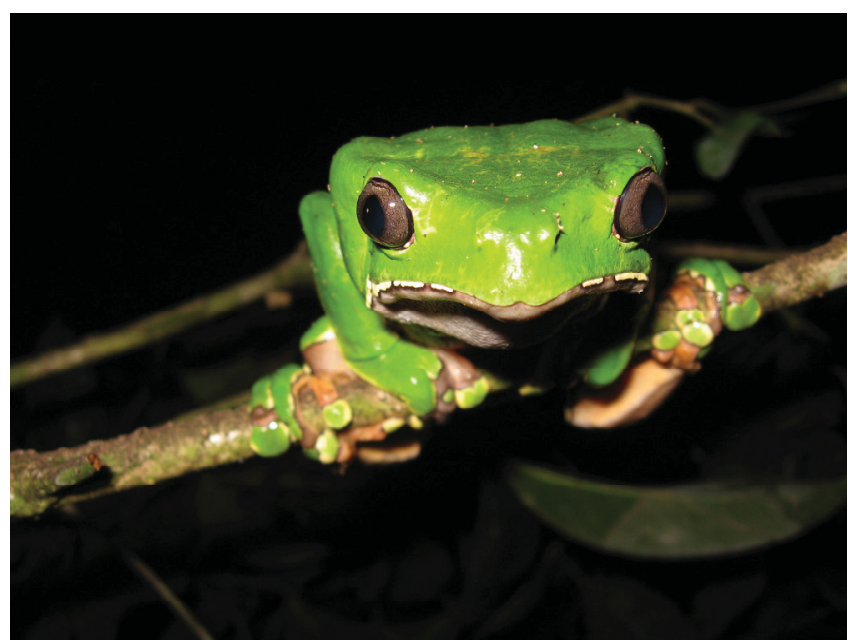

FIGURA 2: Kambô (Phyllomedusa bicolor). Foto por Paulo S. Bernarde.

\section{Resultados}

Foram entrevistadas 31 pessoas no Município de Espigão do Oeste (RO) que receberam a aplicação da "vacina-do-sapo" em 2003, sendo 58\% pertencentes ao sexo masculino. A Idade variou entre 10 a 78 anos, com uma média de 44 anos e a maioria entre 40 a 65 anos.

O grau de escolaridade dos entrevistados foi de 10\% analfabetos, $32 \%$ apresentavam o ensino fundamental, $36 \%$ o ensino médio, 19\% nível superior e 3\% com pós-graduação. Em relação ao perfil da renda mensal, 
a maioria (68\%) dos entrevistados tem renda de mais de cinco salários, $13 \%$ de dois a quatro salários e $19 \%$ possui renda de até um salário mínimo.

Os motivos que os levaram a receber aplicação da "vacina-do-sapo" foram curiosidade e problemas de saúde como reumatismo e diabete. Todos ficaram sabendo da "vacina" através de terceiros (amigos e parentes). Quanto a quantidades de vezes que receberam a aplicação, 39\% receberam apenas uma vez, 55\% receberam pela segunda vez um mês depois, sendo que apenas $6 \%$ receberam a terceira aplicação. $\mathrm{O}$ aplicador não retornou na cidade, por isso, duas pessoas se deslocaram até Porto Velho (cerca de $500 \mathrm{~km}$ ) para receberem a terceira aplicação. Todos entrevistados ouviram falar que a vacina era "boa para tudo".

Dos entrevistados que fizeram uso da "vacina" por curiosidade ou por influência de amigos, $11 \%$ respondeu que houve diminuição de dores de cabeça e $11 \%$ sentiuse mais dispostos. Dos que usaram para diabetes, $71 \%$ disseram não ter apresentado nenhuma melhora. Setenta e cinco por cento dos entrevistados que usaram para reumatismo sentiram-se melhor. Todos que usaram para alergias, dores musculares e gastrite responderam que sentiram uma melhora. Apenas uma pessoa procurou a "vacina" com a intenção de controlar a pressão arterial e disse que não sentiu nenhuma melhora. Cinquenta e dois por cento dos entrevistados respondeu que a "vacina" ajudou no problema de saúde, enquanto que $39 \%$ disse que não, $6 \%$ não notou diferenças e $3 \%$ não soube responder.

Quanto à pergunta se receberiam novamente a aplicação da "vacina do sapo", $52 \%$ disse que sim, 42\% que não e $6 \%$ que não sabia. Em relação ao motivo que usariam novamente, $37 \%$ responderam porque faz bem, $25 \%$ porque funciona e $19 \%$ pelo fato de melhorar a disposição.

A quantidade de pontos e a região anatômica de aplicação foram diferentes entre os sexos masculino e feminino. Nas mulheres as aplicações foram feitas na parte posterior da perna (panturrilha), enquanto nos homens foram feitas na parte externa do braço (deltóide). A quantidade de pontos foi diferente na primeira, segunda e terceira aplicação e entre os sexos (Figuras 3 e 4). As mulheres receberam menos pontos, com uma

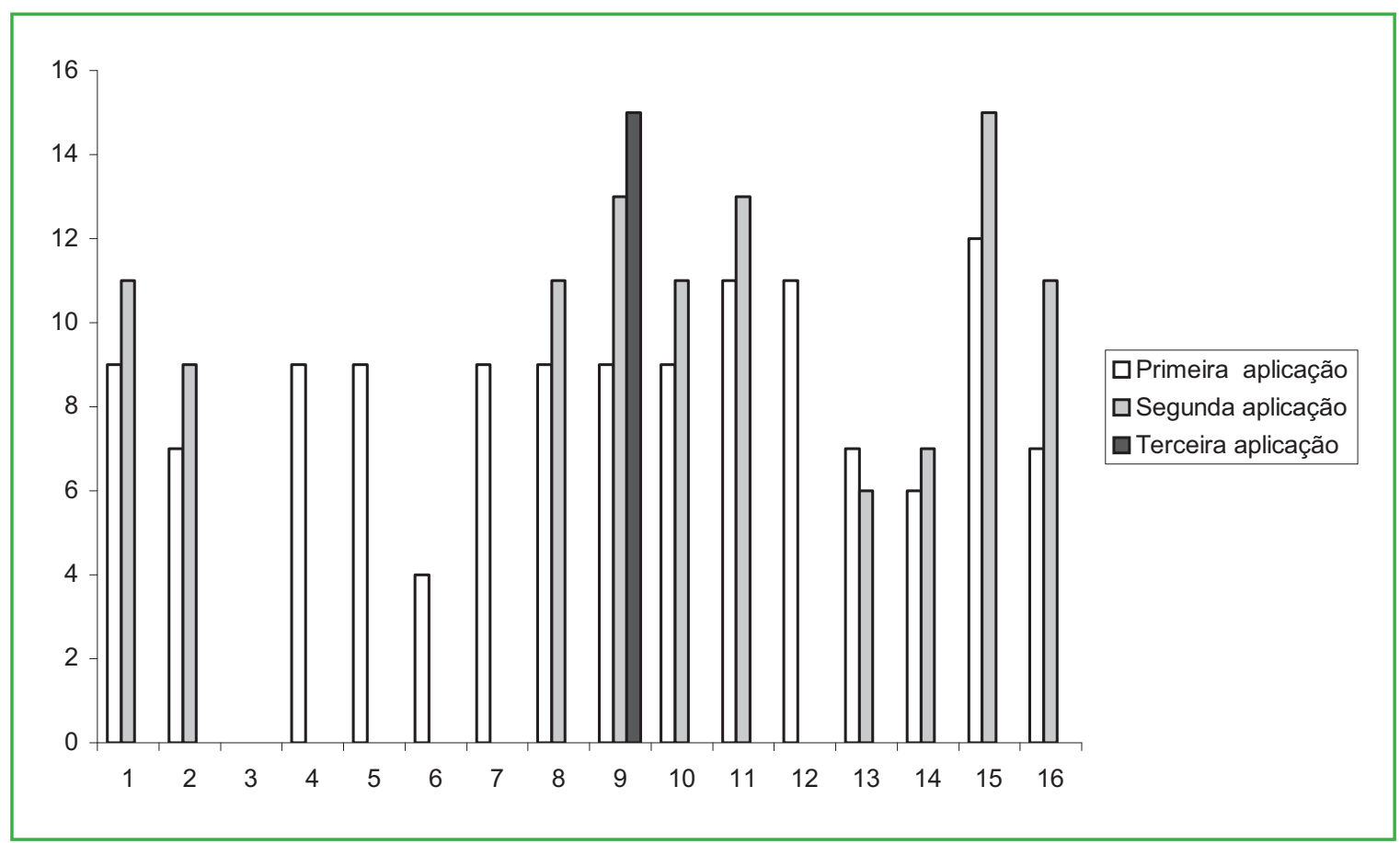

FIGURA 3: Quantidade de pontos durante as primeira, segunda e terceira aplicações da vacina do sapo em indivíduos do sexo masculino em Espigão do Oeste (RO). 


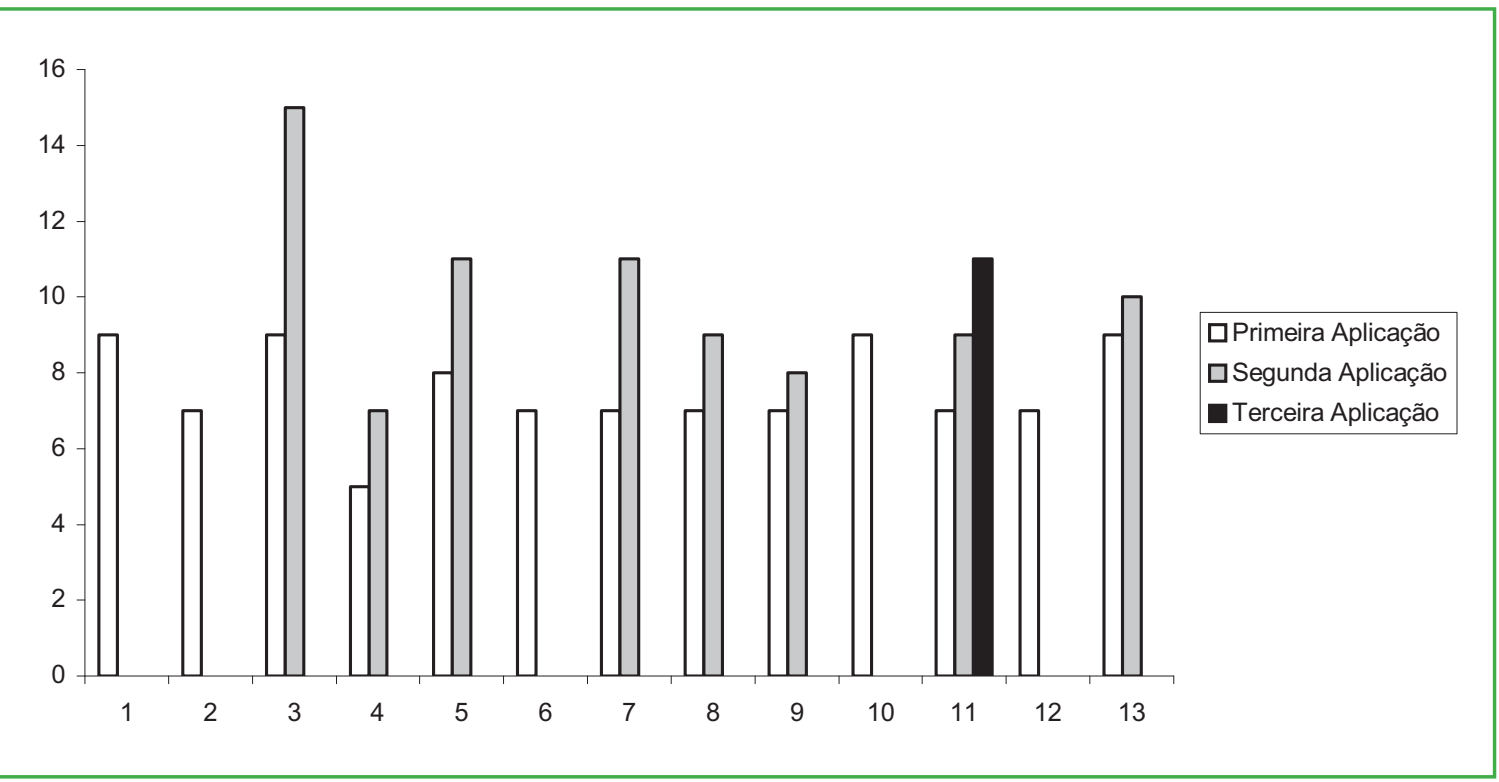

FIGURA 4: Quantidade de pontos durante as primeira, segunda e terceira aplicações da vacina do sapo em indivíduos do sexo feminino em Espigão do Oeste (RO).

média de 8,2 (primeira aplicação) e 10,3 (segunda) do que os homens (média de 8,6 e 11 durante a primeira e segunda aplicação, respectivamente). Sobre os sintomas que sentiram logo após a aplicação os mais comuns foram: calor $(100 \%)$, vermelhidão $(32 \%)$, vertigem (17\%), vômito (12\%) e desmaio (3\%). A duração dos sintomas durou cerca de 15 minutos.

Os valores cobrados foram $\mathrm{R} \$ 50,00$ e $\mathrm{R} \$ 70,00$ pelo tratamento. Cinco dos entrevistados não lembrou o valor pago ao aplicador.

A "vacina-do-sapo" foi aplicada por uma pessoa que disse ser descendente indígena, e quando perguntado aos entrevistados se eles sabiam como o aplicador tinha aprendido a técnica, $65 \%$ respondeu que foi com ancestrais indígenas.

Foi recomendado às pessoas que ingerissem muita água antes da aplicação, que, após a aplicação, tomassem banho com sabão neutro e novo ("virgem"), jogando-o fora em seguida e que colocassem a roupa usada durante o tratamento para lavar.

Sobre o reconhecimento da espécie na prancha apresentada, apenas $13 \%$ reconheceram a Phyllomedusa bicolor e disseram que haviam visto através de reportagens na televisão.

\section{Discussão}

Geralmente fatores sócio-econômicos influenciam na procura de práticas de zooterapia, principalmente por pessoas com pouco acesso aos recursos de saúde que procuram esse tipo de medicina alternativa (Alves et al., 2007; Alves, 2009). O alto número de espécies de animais registrado em alguns estudos demonstra a importância dessa prática para essas pessoas (Alves, 2009). Nesse estudo, pessoas de classe média a alta (com renda de mais de cinco salários mínimos) e que apresentam relativamente bom nível de escolaridade que utilizaram a "vacina-do-sapo". Enquanto na sua região de origem (Acre), a utilização da "vacina-do-sapo" ("kambô") é um recurso tradicional para as populações humanas que vivem nas florestas (indígenas e extrativistas) com difícil acesso a medicina urbana (Souza et al., 2002), em outras regiões esse tipo de terapia é procurada por pessoas com nível financeiro relativamente maior e acesso aos recursos de saúde (Lima e Labate, 2007; presente estudo).

Enquanto os índios utilizam a "vacina-do-sapo" para afastar a "panema" e diversos males, perfazendo um ritual com significado espiritual (Souza et al., 2002; Lima e Labate, 2007), os usuários não-indígenas procuraram esse tratamento para alguns problemas 
específicos (gastrite, reumatismo, diabete, alergias, etc.) e também por curiosidade. Apenas cerca da metade dos entrevistados (52\%), disse que a vacina ajudou em alguma melhoria e que receberia a aplicação novamente. Em um folheto sobre propaganda da "vacina-do-sapo" em São Paulo constava mais de 30 enfermidades das quais ela poderia ser eficaz (Lima e Labate, 2007), como exemplo baixa imunidade, dor de cabeça, gastrite, diabetes, pressão arterial alta, cirrose, labirintite, epilepsia, impotência e depressão.

Apesar de ocorrerem quatro espécies de Phyllomedusa (P. camba, P. hypochondrialis, P. tomopterna e $P$. vaillanti) em Espigão do Oeste (Bernarde et al., 1999; Bernarde, 2007), a maioria das pessoas (87\%) não conhece o anfíbio que produz a secreção. Isso pode gerar problemas no futuro, caso algumas pessoas resolvam realizar a aplicação e capturem e retirem veneno de alguma espécie tóxica (Lima e Labate, 2007). Sapos do gênero Rhinella apresentam veneno cardiotóxico (Monti e Cardello, 1999), que pode causar parada cardíaca. O uso de espécies erradas na aplicação poderia resultar em problemas de saúde.

Segundo os entrevistados mais de 100 pessoas receberam as aplicações em cada uma das vezes que o aplicador foi ao município. Isso significaria um ganho de cerca de 7000,00 Reais, apenas nesta vez. Com a propaganda de que a "vacina" serve para tudo, muitas pessoas ficam insatisfeitas por não obterem o resultado desejado. Devido ao objetivo de ter lucro, muito da tradição dessas aplicações pode ter sido modificado e distorcido na realização dessa prática em sua região de origem (Souza et al., 2002; Lima e Labate, 2007). As secreções de algumas espécies de Phyllomedusa estão sendo estudadas para fins medicinais, especialmente para a produção de antibióticos (Daly et al., 1992; Prates e Bloch Jr., 2000; Leite et al., 2004). A Agência Nacional de Vigilância Sanitária determinou a suspensão de todo tipo de propaganda dessa alternativa terapêutica, considerando que não existe comprovação científica que garanta qualidade, segurança e eficácia da substância extraída da Phyllomedusa bicolor, conhecida como "Kambô - Vacina-do-sapo" com indicação para qualquer tipo de distúrbio, desequilíbrio ou tratamento de quaisquer processos agudos e crônicos (ANVISA, 2004).
$\mathrm{O}$ uso e difusão da vacina-do-sapo aumentam a oportunidade de biopirataria e violação dos direitos dos povos indígenas detentores desse conhecimento tradicional. Os índios da língua Pano na fronteira entre o Brasil e Peru são os que originalmente utilizam essa vacina (Daly et al., 1992; Souza et al., 2002). No Acre, alguns seringueiros aprenderam essa técnica com os índios Katukina e Kaxinawá (Souza et al., 2002). Várias patentes já foram produzidas a partir da secreção de Phyllomedusa bicolor por pesquisadores estrangeiros (Amazonlink.org, 2009) e devido ao potencial farmacológico dos peptídeos isolados dessa espécie (Daly et al., 1992; Prates e Bloch Jr., 2000; Leite et al., 2004), existe o risco de apropriação ilegal desse conhecimento tradicional. Os índios Katukina estão preocupados com a utilização ilegal do veneno por parte de terapeutas urbanos e cientistas (Lima e Labate, 2007).

Outro aspecto a ser considerado é o fato de que o uso de animais para fins medicinais requer a retirada destes na natureza, necessitando-se assim de estudos sobre possíveis impactos nas populações dessas espécies (Alves e Rosa, 2005; Alves e Pereira-Filho, 2007; Alves et al., 2007; 2008). Apesar de que a secreção é retirada da pele do anfíbio vivo e este devolvido à natureza (Daly et al., 1992; Souza et al., 2002), não existe nenhum estudo se esses espécimes sofrem algum tipo de injúria durante o processo de coleta do veneno e se eles se tornam mais vulneráveis à predação. A secreção retirada é guardada de forma cristalizada em "palhetas" de madeira para ser transportado e usada no momento da aplicação (Daly et al., 1992). Essas palhetas são vendidas pelos índios ou por pessoas que aprenderam a técnica de retirar o veneno de Phyllomedusa bicolor no Acre para os terapeutas urbanos que realizam aplicações em várias cidades no Brasil (Lima e Labate, 2007; observação pessoal).

A utilização da "vacina-do-sapo" em Espigão do Oeste não se trata de um hábito tradicional da região, sendo que o aplicador veio de outra parte da Amazônia. Em geral, as pessoas que utilizaram a vacina são de classe média a alta e apresentam algum nível de escolaridade (ensino fundamental, médio ou superior). Cerca de metade dos entrevistados acharam que as aplicações ajudaram no problema de saúde que as levaram a receber 
a vacina ou sentiram melhor disposição após o tratamento e fariam novamente as aplicações. A maioria das pessoas não conhece a espécie Phyllomedusa bicolor, do qual é retirada a secreção para elaboração da vacina. Apesar de que várias pessoas procuraram o tratamento achando que a vacina seja eficaz contra várias enfermidades, suas propriedades medicinais ainda se encontram em estudo. É necessária uma fiscalização contra a venda ilegal do veneno cristalizado em palhetas e estudos sobre possíveis impactos nas populações de P. bicolor.

\section{Agradecimentos}

A Reginaldo A. Machado pela leitura do manuscrito. Aos dois revisores anônimos pelas sugestões.

\section{Referências}

Alves, R. R. N. 2009. Fauna used in popular medicine in Northeast Brazil. Journal of Ethnobiology and Ethnomedicine, 5 (1): 1-11.

Alves, R. R. N.; Pereira-Filho, G. A. 2007. Commercialization and use of snakes in North and Northeastern Brazil: Implications for conservation and management. Biodiverstity and Conservation, 16: 969-985.

Alves, R. R. N.; Rosa, I. L. 2005. Why study the use of animal products in traditional medicines? Journal of Ethnobiology and Ethnomedicine, 1: 1-5.

Alves, R. R. N.; Rosa, I. L. 2007. Zootherapy góes to town: The use of animal-based remedies in urban áreas of NE and $\mathrm{N}$ Brazil. Journal of Ethnopharmacology, 113: 541-555.

Alves, R. R. N.; Rosa, I. L.; Santana, G. G. 2007. The role of animal-derived remedies as complementary medicine in Brazil. BioScience, 57 (11): 949-955.

Alves, R. R. N.; Soares, T. C.; Mourão, J. S. 2008. Uso de animais medicinais na comunidade de Bom Sucesso, Soledade, Estado da Paraíba, Brasil. Sitientibus Série Ciências Biológicas, 8 (2) : 142147.

Amazonlink.org. 2009. Amazonlink.org. Disponível em <http:// www.amazonlink.org/>. Acesso em 13 de abril de 2009.

Amiche, M.; Ducancel, F.; Mor, A.; Boulain, J. C.; Menez,A.; Nicolas, P. 1994. Precursors of vertebrate peptide antibiotics dermaseptine $b$ and adenoregulin have extensive sequence identities with precursors of opioid peptides dermophin, dermenkephalin, and deltorphins. Journal of Biological Chemistry, 269 (27): 17847-17852.

ANVISA. 2004. Resolução-RE Nº, de 29 de Abril de 2004. Agência Nacional de Vigilância Sanitária. Diário Oficial da União, Brasília, DF, Seção $1 \mathrm{~N}^{\circ}$ 82, p. 94, 30 abr.

Bernard, H. R. 1996. Research methods in anthropology: Qualitative and quantitative approaches. American Journal of Evaluation, 17: $91-92$.
Bernarde, P. S. 2007. Ambientes e temporada de vocalização da anurofauna no Município de Espigão do Oeste, Rondônia, Sudoeste da Amazônia - Brasil (Amphibia: Anura). Biota Neotropica, 7 (2): 87-92.

Bernarde, P. S.; Kokubum, M. C. N.; Machado, R. A.; Anjos, L. dos. 1999. Uso de habitats naturais e antrópicos pelos anuros em uma localidade no Estado de Rondônia, Brasil (Amphibia: Anura). Acta Amazônica, 29 (4): 555-562.

Brand, G. D.; Leite, J. R.; Silva, L. P.; Albuquerque, S.; Prates, M. V.; Azevedo, R. B.; Carregaro, V.; Silva, J. S.; Sá, V. C.; Brandao, R. A.; Bloch Jr., C. 2002. Dermaseptins from Phyllomedusa oreades and Phyllomedusa distincta: Anti-Trypanosoma cruzi activity without cytotoxicity to mammalian cells. Journal of Biological Chemistry, 277 (51): 49332-49340.

Caramaschi, U.; Cruz, C. A. G. 2002. Phyllomedusa: Posição taxonômica, hábitos e biologia (Amphibia, Anura, Hylidae). Phyllomedusa, 1 (1): 5-10.

Clarke, B. T. 1997. The natural history of amphibian skin secretions, their normal functioning and potential medical applications. Biological Reviews, 72 (3): 365-379.

Costa-Neto, E. M. 2005. Animal-based medicines: Biological prospection and the sustainable use of zootherapeutic resources. Anais da Academia Brasileira de Ciências, 77 (1): 33-43.

Costa-Neto, E. M.; Resende, J. J. 2004. A percepção de animais como "insetos" e sua utilização como recursos medicinais na cidade de Feira de Santana, Estado da Bahia, Brasil. Acta Scientiarum, 26 (2): 143-149.

Daly, J. W. 1998. Thirty years of discovering arthropod alkaloids in amphibian skin. Journal of Natural Products, 61 (1): 162-172.

Daly, J. W.; Caceres, J.; Moni, R. W.; Gusovsky, F.; Moos Jr, M.; Seamon, K. B.; Milton, K.; Myers, C. W. 1992. Frog secretions and hunting magic in the upper Amazon: Identification of a peptide that interacts with an adenosine receptor. Proceedings of the National Academy of Sciences USA, 89 (22): 10960-10963.

Duellman, W. E.; Trueb, L. 1994. Biology of Amphibians. McGraw Hill Book Co., New York, USA, 577pp.

Elisabetsky, E. 2003. Etnofarmacologia. Ciência e Cultura, 55 (3): 35-36.

Leite, J. R. S. A.; Silvac, L. P.; Rodrigues, M. I. S.; Prates, M. V.; Brand, G. D.; Lacava, B. M.; Azevedo, R. B.; Boccad, A. L.; Albuquerque, S.; Bloch Jr., C. 2004. Phylloseptins: A novel class of anti-bacterial and anti-protozoan peptides from the Phyllomedusa genus. Peptides, 26 (4): 565-573.

Lima, E. C.; Labate, B. C. 2007. "Remédio da Ciência" e "Remédio da Alma": Os usos da secreção do Kambô (Phyllomedusa bicolor) nas cidades. Campos, 8 (1): 71-90.

Monti, R.; Cardello, L. 1999. Bioquímica do veneno de anfíbios. In: Barraviera, B. (Ed.). Venenos: Aspectos clínicos e terapêuticos dos acidentes por animais peçonhentos. EPUB, Rio de Janeiro, Brasil, p.225-232.

Myers, C. W.; Daly, J. W.; Malkin, B. 1978. A dangerously toxic new frog (Phyllobates) used by Embera Indians of western Colombia, with discussion of blowgun fabrication and dart poisoning. Bulletim American Museum of Natural History, 161: 307-366.

Oliveira, O. A 2002. Geografia de Rondônia - Espaço e produção. Dinâmica Editora e Distribuidora Ltda, Porto Velho, Brasil, 160pp. 
Prates, M. V.; Bloch Jr., C. 2000. Peptídeos antimicrobianos - Uma alternativa no combate a microorganismos resistentes. Biotecnologia, Ciência e Desenvolvimento, Brasília, 17: 30-36.

Rodrigues, E. 2006. Plants and animals utilized as medicines in the Jaú National Park (JNP), Brazilian Amazon. Phytotherapy Research, 20: 378-391.

Santos-Fita, D.; Costa-Neto, E. M. 2007. As interações entre os seres humanos e os animais: a contribuição da etnozoologia. Biotemas, 20 (4): 99-110.

Souza, M. B.; Cataiano, C.; Aquino, T. V. de; Lima, E. C.; Mendes, M. K. 2002. Anfíbios. In: Cunha, M. C. \& Almeida, M. B. (Orgs). Enciclopédia da floresta. OAlto Juruá: Práticas e conhecimentos das populações. Companhia das Letras, São Paulo, Brasil, p.601614.

Vasconcelos-da-Silva, M. L.; Alves, A. G. C.; Almeida, A. V. 2004. A zooterapia no Recife (Pernambuco): Uma articulação entre as práticas e a história. Biotemas, 17 (1): 95-116.

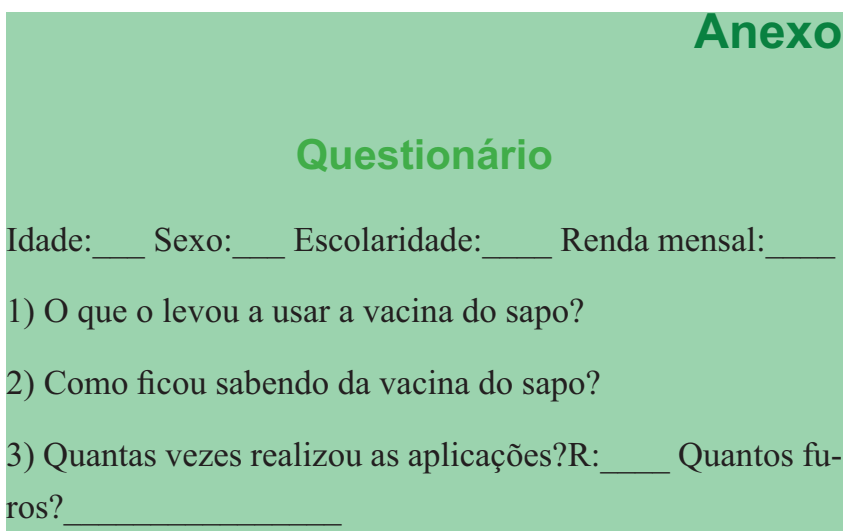

Em que região anatômica? Braço ( ) Perna ( )

Outra :

Qual o intervalo de tempo entre uma aplicação e outra? R:

Quanto pagou? R:

4) Quem fez?

5) Como o aplicador aprendeu a técnica (fazer isso)?

6) Que sintomas sentiu após poucos minutos da aplicação?

Vômitos ( ) Diarréia ( ) Ficou vermelho( )

Tontura ( )

Outros:

7) Quanto tempo durou o efeito? R: Sentiu-se melhor depois? R

8) Acha que a vacina ajudou no problema? R:

9) Usaria novamente a vacina do sapo?R:

10) Para que serve a vacina? Ouviu dizer que ela serve para que?

11) Quais as recomendações antes e após a aplicação?

12) Reconhece a espécie que retira o veneno pra fazer a vacina? R:

Qual foto? R: 